\title{
UK Prospective Diabetes Study (UKPDS)
}

\section{Study design, progress and performance}

\author{
UK Prospective Diabetes Study Group \\ Radcliffe Infirmary, Oxford; Royal Infirmary, Aberdeen; General Hospital, Birmingham; St George's Hospital and Hammersmith Hospital, \\ London; City Hospital, Belfast; North Staffordshire Royal Infirmary, Stoke-on-Trent; Royal Victoria Hospital, Belfast; St. Helier Hospital, \\ Carshalton; Whittington Hospital, London; Norfolk and Norwich Hospital; Lister Hospital, Stevenage; Ipswich Hospital; Ninewells \\ Hospital, Dundee; Northampton Hospital; Torbay Hospital, Peterborough General Hospital; Scarborough Hospital; Derbyshire Royal \\ Infirmary; Manchester Royal Infirmary; Hope Hospital, Salford; Leicester General Hospital; Royal Devon and Exeter Hospital, Exeter, UK \\ This manuscript was prepared by R. C. Turner, R. R. Holman, D. R. Matthews, S. F. Oakes, P. A. Bassett, I. M. Stratton, C. A. Cull, \\ S. E. Manley and V. Frighi
}

Summary. The UK Prospective Diabetes Study (UKPDS) is a multi-centre, prospective, randomised, intervention trial of 5100 newly-diagnosed patients with Type 2 (non-insulin-dependent) diabetes mellitus which aims to determine whether improved blood glucose control will prevent complications and reduce the associated morbidity and mortality. Newly presenting Type 2 diabetic patients aged 25-65 years inclusive, median age 53 years, median body mass index $28 \mathrm{~kg} / \mathrm{m}^{2}$ and median fasting plasma glucose $11.3 \mathrm{mmol} / \mathrm{l}$, were recruited and treated initially by diet. Ninety five percent remained hyperglycaemic (fasting plasma glucose $>6 \mathrm{mmol} / \mathrm{l}$ ) and were randomly allocated to different therapies. In the main randomisation, those who were asymptomatic and had fasting plasma glucose under $15 \mathrm{mmol} / \mathrm{l}$ were allocated either to diet policy, or to active policy with either insulin or sulphonylurea aiming to reduce the fasting plasma glucose to under $6 \mathrm{mmol} / 1$. Over 3 years, the median fasting plasma glucose in those allocated to diet policy was $8.9 \mathrm{mmol} / 1 \mathrm{com}$ pared with $7.0 \mathrm{mmol} / \mathrm{l}$ in those allocated to active policy. The Hypertension in Diabetes Study has been included in a factorial design to assess whether improved blood pressure control will be advantageous. Patients with blood pressure $\geq 160 / 90 \mathrm{~mm} \mathrm{Hg}$ were randomly allocated to tight control aiming for $<150 / 85 \mathrm{~mm} \mathrm{Hg}$ with either an angiotensin-converting enzyme inhibitor or a Beta-blocker or to less tight control aiming for $<200 / 105 \mathrm{~mm} \mathrm{Hg}$. The endpoints of the studies are major clinical events which affect the life and well-being of patients, such as heart attacks, angina, strokes, amputations, blindness and renal failure. To date, $728 \mathrm{pa}-$ tients have had at least one clinical endpoint. Surrogate endpoints include indices of macrovascular and microvascular disease detected by ECG with Minnesota Coding, retinal colour photography and microalbuminuria. The studies also aim to evaluate potential risk factors for the development of diabetic complications such as smoking, obesity, central adiposity, plasma LDL- and HDL-cholesterol, triglyceride, insulin, urate and other biochemical variables. The studies are planned to terminate in 1994, with a median follow-up of 9 years (range 3-16 years) for the glucose study and 5 years (range 2-6 years) for the hypertension study.

Key words: Type 2 (non-insulin-dependent) diabetes mellitus, hypertension, complications, clinical trial, glycaemic control, blood pressure control.
Diabetes mellitus is one of the most common chronic diseases with an overall prevalence in white Caucasian populations of approximately $2 \%$. The vast majority is Type 2 (non-insulin-dependent) diabetes, occurring in middle or old age, and at least $4 \%$ of people in their 60 's have diabetes $[1,2]$. It is associated with an approximately three-fold risk of all cardiovascular diseases [3] and a substantial reduction in life expectancy [4]. In those presenting in their 40's and early 50's, there is a two-fold increased mortality compared with a control population [5]. Diabetes is a major cause of blindness, renal failure and amputations, all of which require expensive health-care resources. In the UK, the cost of diabetes care is in the order of $£ 1$ billion per annum [6].
The continued high incidence of complications in Type 2 diabetic patients $[4,7]$ indicates that the current therapeutic approach is inadequate for maintaining good health. It is not known whether the therapies are insufficiently strictly applied, so that variables such as blood glucose or blood pressure remain too high, or whether any specific therapy has advantages over others. Only a prospective study of different therapies can determine which may be effective in preventing complications. Until firm data are available, much of the care which is currently given in diabetic clinics and general practice may be misdirected.

The aims of the UK Prospective Diabetes Study (UKPDS) and of the Hypertension in Diabetes Study (HDS) are listed in Table 1. Evidence that a particular 
Table 1. Long-term aims of studies

\section{UK Prospective Diabetes Study}

To determine whether treatment aiming for near-normal plasma glucose levels, $<6 \mathrm{mmol} / \mathrm{l}$, reduces morbidity and improves life expectancy

To determine whether diet alone, sulphonylurea, insulin or metformin therapy has a particular advantage in terms of improving prognosis.

\section{Hypertension in Diabetes Study}

To determine whether treatment aiming for a near-normal blood pressure, systolic $<150 \mathrm{~mm} \mathrm{Hg}$ and diastolic $<85 \mathrm{mmHg}$, reduces morbidity and improves life expectancy

To determine whether therapy with an angiotensin-converting enzyme inhibitor or a Beta-blocker has a particular advantage in improving prognosis.

\section{Both studies}

To determine whether any specific therapy has deleterious major side effects.

To determine whether certain clinical and laboratory measure ments, including both possible risk factors and indices of early vascular disease, are useful predictors of subsequent complications.

To determine whether any of the therapies have health care ad vantages, decreasing the number of days of lost normal activity or the number of hospital admissions.

therapeutic approach is beneficial could lead (a) to lower mortality, heart attacks, strokes, amputations, blindness and renal failure arising from diabetes and (b) to the introduction of a screening programme to detect diabetes and hypertension before complications develop.

\section{Blood glucose control}

Although prospective studies have shown an association of hyperglycaemia with retinopathy [8-11], short-term intervention studies on the effect of strict glycaemic control on the progression of retinopathy have led to inconclusive results [12-14]. In Type 1 (insulin-dependent) diabetic patients, if strict normoglycaemia is induced by a pancreas transplant, the progress of diabetic nephropathy in a renal transplant [15] and of peripheral neuropathy [16] is retarded, but no studies of intensive medical therapies have shown that strict glycaemic control prevents complications. Thus, it is uncertain whether improved therapy of Type 2 diabetes with available medications would be advantageous.

A raised basal plasma glucose is a major feature of Type 2 diabetes [17] which can be assessed by routine measurement of the fasting blood glucose concentration [18]. A logical control criterion is to aim for normal basal glucose concentrations [19]. The epidemiological association between hyperglycaemia and the subsequent incidence of diabetic retinopathy $[8,9]$ suggests that a fasting plasma glucose greater than $7.8 \mathrm{mmol} / \mathrm{l}$ is a risk factor for microvascular disease. This is the basis for the current World Health Organisation (WHO) classification of diabetes [20]. Blood glucose levels at the upper end of the normal range (approximating to a fasting plasma glucose $>6 \mathrm{mmol} / \mathrm{l}$ ) have been associated with a greater incidence of cardiovascular disease [21, 22]. However, this issue remains controversial because of discordant results [23] and because other associated risk factors may be involved [24-26].

The University Group Diabetes Program (UGDP) prospective study of Type 2 diabetes showed no clinical benefit from insulin or sulphonylurea therapy and suggested that tolbutamide induced an increased cardiovascular mortality [27]. Nevertheless, sulphonylurea therapy appears to be safe for patients with impaired glucose tolerance $[28,29]$ and the UGDP was too small with too fewendpoints to allow reliable conclusions. In addition, by the end of the study the groups with good control using sulphonylurea or variable insulin had a mean fasting blood glucose of 8.6 and $6.8 \mathrm{mmol} / 1$ respectively $[7,27]$ equivalent to a fast-

Table 2. Randomised allocations of the 4072 patients in Glucose Study I, together with the comparison groups for major endpoint analyses

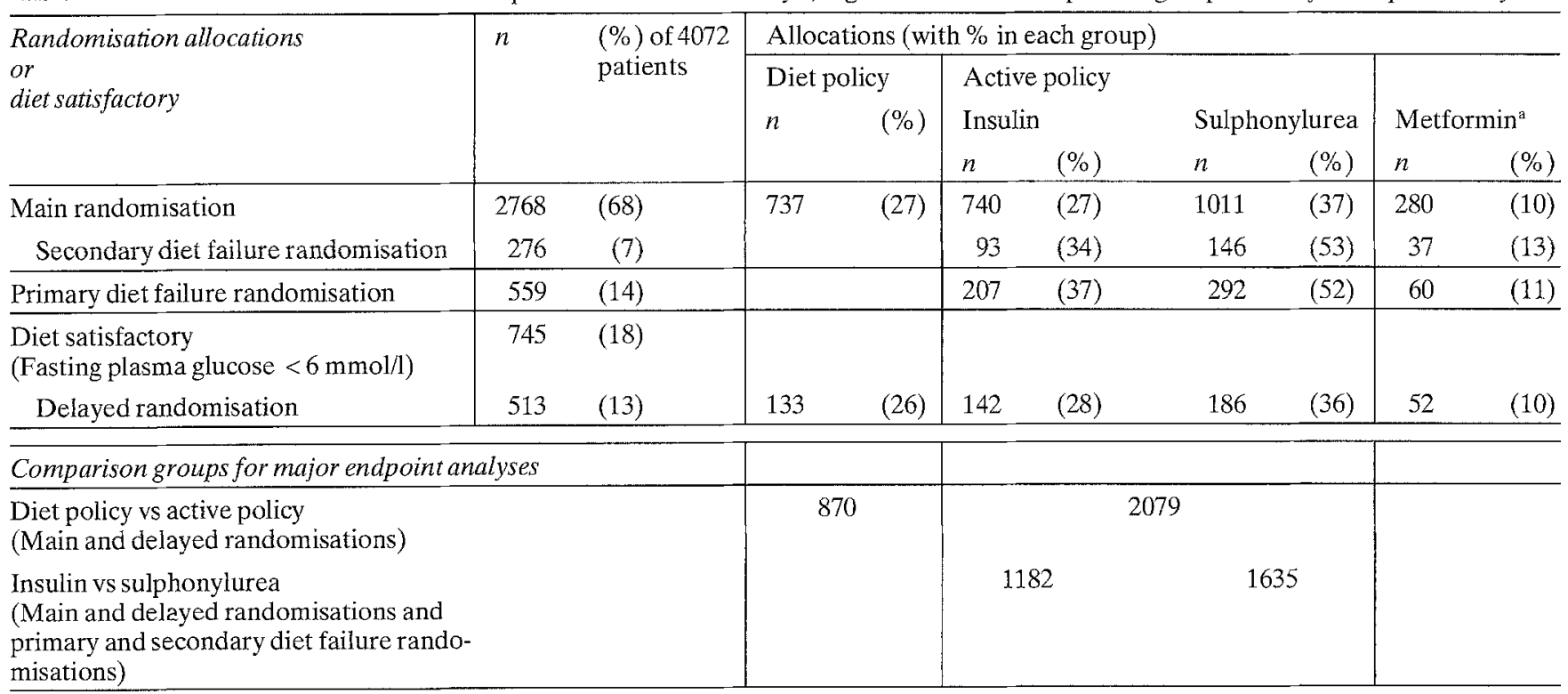

a Obese patients only 


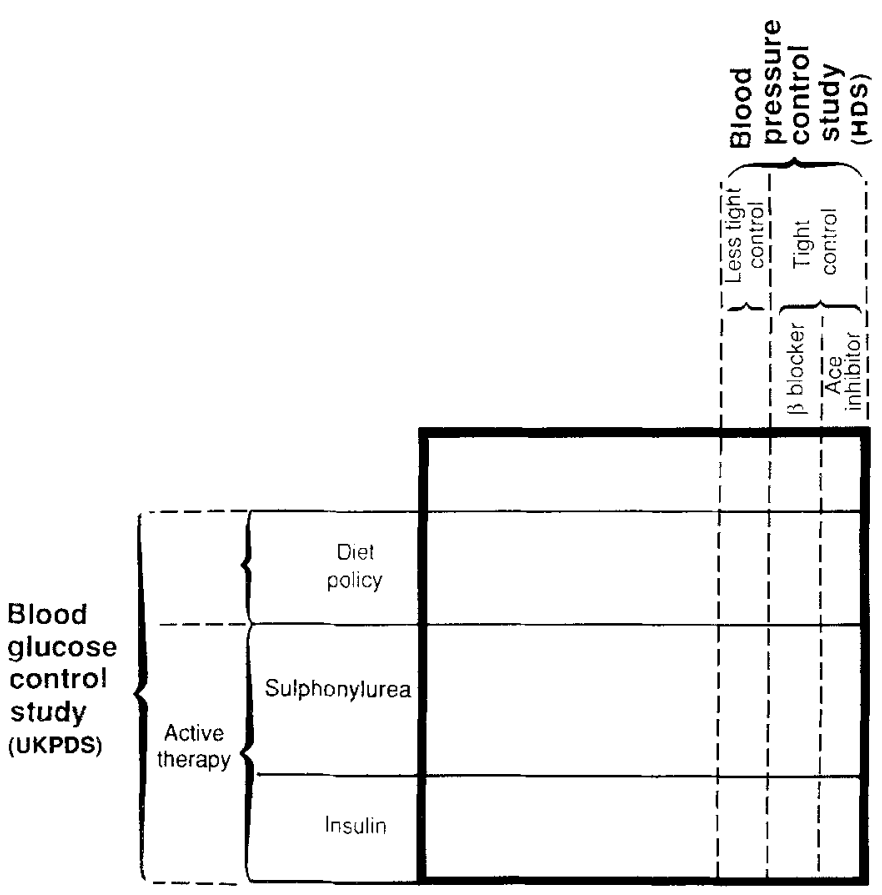

Fig. 1. Representation of factorial design in which the bold square represents the total number of patients recruited. Patients can be included in the independent blood glucose control study (UKPDS), represented by the vertical divisions, and in the blood pressure control study (HDS), represented by the horizontal divisions. Ace $=$ angiotensin-converting enzyme

ing plasma concentration of 9.6 and $7.6 \mathrm{mmol} / \mathrm{l}$ respectively and these may be above a threshold of benefit. The Diabetes Control and Complication Trial is a study of improved glycaemic control in Type 1 diabetes that has predominantly microvascular endpoints, e.g. progress of retinopathy and of renal disease [30] and is not primarily planned to assess mortality or major morbidity.

The UK Prospective Diabetes Study was designed primarily to determine whether aiming for near-normoglycaemia (fasting plasma glucose $<6 \mathrm{mmol} / \mathrm{l}$ ) in Type 2 diabetic subjects would prevent major complications and early mortality. It secondarily compares insulin and sulphonylurea therapy Table 1. As sulphonylurea stimulates endogenous insulin secretion and insulin therapy provides exogenous insulin, it is assumed that any advantage would be due to a reduction of hyperglycaemia by increasing insulin supply rather than to the therapies per se. On the other hand, metformin is thought to act by improving insulin sensitivity [31] and a group allocated to metformin therapy has been included.

\section{Blood pressure control}

Hypertension in Type 2 diabetic subjects is associated with an increased risk of macrovascular complications [32] but no blood pressure intervention trials have been carried out in such patients. In non-diabetic hypertensive subjects, the Medical Research Council [33] and the Australian National Blood Pressure [34] studies showed that hypotensive therapy reduced the rate of strokes by half. A recent overview of many trials has suggested that therapy also leads to $14 \%$ reduction in the risk of myocardial infarcts [35]. However, the side-effects of therapy are considerable and many physicians feel that in the general population the benefit from therapy of mild to borderline hypertension does not outweigh the high prevalence of side-effects [36]. This situation may not pertain equally to diabetic patients, in whom the risk of vascular events is two-three times greater than in the normal population [3] and in whom microvascular disease is also a problem. In Type 1 diabetic patients hypertension therapy retards the progression of microalbuminuria [37]. In patients with overt nephropathy with albuminuria, improved blood pressure control reduces the rate of decline of the glomerular filtration rate $[38,39]$ and may have contributed to the improvement in survival, with preserved kidney function, observed within the last 20 years [ 40 ]. However, it is unknown whether in Type 2 diabetes routine therapy of hypertension would prevent the onset or progress of diabetic tissue damage.

Whether any specific hypotensive therapy has a particular advantage is uncertain. Beta-blocker therapy

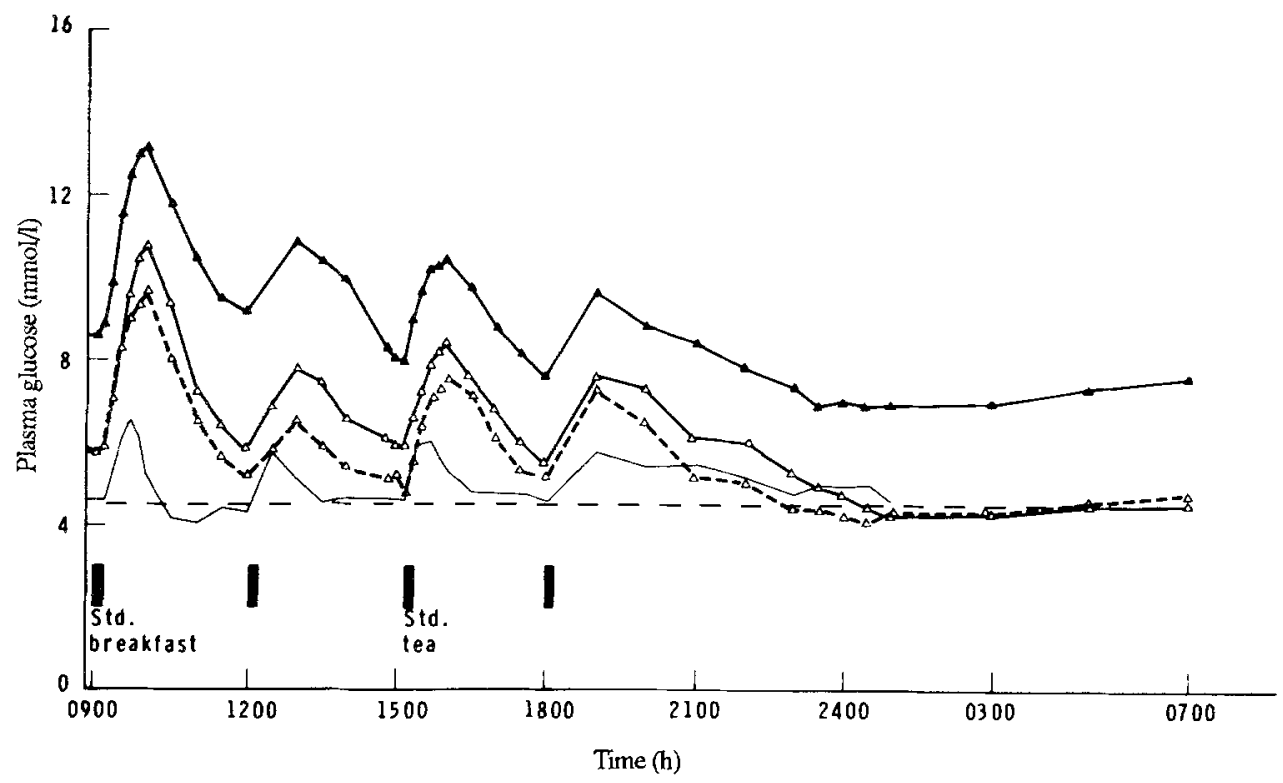

Fig. 2. Example of blood glucose control which could be achieved in the main randomisation. Results show 24-h glucose profiles from a cross-over study of 13 Type 2 (noninsulin-dependent) diabetic patients studied on diet alone ( $\downarrow$ ), and on treatment with additional ultralente insulin $(-\Delta-\Delta-)$ or with additional chlorpropamide $(\Delta \Delta)$, compared with 8 normal subjects (-) (ref. 41 with permission) 
might have a protective effect against cardiac mortality $[41,42]$. Angiotensin-converting enzyme (ACE) inhibitors decrease albuminuria in hypertensive [43] and normotensive [44] Type 1 diabetic patients, possibly by reducing glomerular capillary hypertension $[45,46]$. The renin-angiotensin system could play a role in the development of cardiovascular disease [47-51] and animal studies have suggested that ACE inhibitors might retard a pathophysiological process leading to the development of atheroma [52, 53]. However, as no long-term morbidity and mortality data are available, the clinical benefits of ACE inhibitors remain hypothetical [54].

In view of the high prevalence of hypertension found in the UKPDS [55] and of the uncertainties regarding its treatment, a random allocation of different therapies was introduced in 1987 in a factorial design (Fig. 1). The blood pressure study is independent from the glucose control study, is termed the Hypertension in Diabetes Study (HDS) and will be analysed separately. The study was designed primarily to determine whether aiming for nearnormal blood pressure (systolic $<150$ and diastolic $<85 \mathrm{~mm} \mathrm{Hg}$ ) is of clinical benefit and secondarily to compare ACE-inhibitor and Beta-blocker therapy of hypertension in Type 2 diabetes (Table 2).

This paper describes the Glucose Study, the Hypertension Study, the management of the studies and the outcome variables.

\section{Subjects and methods}

\section{Blood glucose control study - UK Prospective Diabetes Study (UKPDS)}

The study was started in 1977 and included 600 patients in a pilot phase in five centres [56]. This was extended to 15 centres (Glucose Study I) in 1982 and included assessment of retinopathy by colour fundal photography and central collection of biochemical samples. A further eight centres (Glucose Study II) were started in 1987. A total of 5100 patients have been recruited. The clinical study is planned to finish in early 1994 with a median follow-up of 9 years.

\section{Study design}

Patients with newly-diagnosed diabetes were recruited and treated initially with diet for 3 months. Those who remained symptom-free but who had continuing fasting hyperglycaemia, plasma glucose $>6.0$ and $<15.0 \mathrm{mmol} / \mathrm{l}$ were randomly allocated to active policy or to diet policy in the main randomisation. In the diet policy group the aim was to maintain patients free of diabetic symptoms and with a fasting plasma glucose $\leq 15 \mathrm{mmol} / \mathrm{l}$. In the active policy group, the aim was to maintain basal normoglycaemia (fasting plasma glucose $<6 \mathrm{mmol} / \mathrm{l}$ ). Two main therapies were studied: sulphonylurea [57] or a basal insulin supplement [19] provided by ultralente insulin given once per day [58]. Control achieved with this insulin regimen can be similar to that obtained with sulphonylurea [57] (Fig. 2). With both therapies there was minimal risk of hypoglycaemia and no need to take special care about individual meal sizes. In Glucose Study I obese patients could also be randomised to metformin.

Recruitment and selection criteria. Local general practitioners were asked to refer all newly-diagnosed diabetic patients aged 2565 years inclusive to the centres. The patients were seen in a UKPDS clinic, usually within 2 weeks from their doctor's referral. If reasonable, oestrogen therapy and thiazides were stopped before assessment, with the alternative of a loop diuretic (frusemide), if required.
The fasting plasma glucose was measured from a venous sample in the hospital clinic after an overnight fast from 22.00 hours. In the morning only drinks of water were allowed before blood sampling. If diabetes was confirmed (main criterion fasting plasma glucose $>6 \mathrm{mmol} / \mathrm{l}$ on two occasions) the patients were asked if they wished to participate in a prospective study, of whom $85 \%$ had a fasting plasma glucose above the WHO criterion of $7.8 \mathrm{mmol} / \mathrm{l}$. A 2 -h plasma glucose value $\geq 11 \mathrm{mmol} / 1$ in the oral glucose tolerance test (OGTT) is the main WHO diagnostic criterion for diabetes. A 75-g OGTT was done in 216 UKPDS subjects at diagnosis. Regression analysis $(y=0.50 \mathrm{x}+1.54)$ showed that a fasting plasma glucose value of $7.1 \mathrm{mmol} / \mathrm{l}$ was equivalent to a $2-\mathrm{h}$ value of $11.1 \mathrm{mmol} / 1$. Using this fasting plasma glucose criterion, $92 \%$ of all UKPDS patients would be expected to have fulfilled the WHO criteria for diabetes.

Patients were told that there was uncertainty about which therapy was best if diet alone failed to control their diabetes, and that the decision would then be randomised. Of the referred patients $28 \%$ did not enter the study because of the exclusion criteria, i.e. ketonuria $>3 \mathrm{mmol} / \mathrm{l}$, a history of myocardial infarction in the previous year, current angina or heart failure, more than one major vascular episode, serum creatinine $>175 \mu \mathrm{mol} /$, severe retinopathy requiring photocoagulation, malignant hypertension, an uncorrected endocrine abnormality, an occupation which would not allow randomization to insulin therapy (e.g. heavy goods vehicle driver), a severe concurrent illness likely to limit life (e.g. cancer) or requiring extensive systemic treatment (e.g. ulcerative colitis), or inadequate comprehension to allow co-operation [56]. The enrolled patients were intially treated by diet and seen monthly for 3 months when the major entry point to the study was at a formal therapy decision randomisation.

Initial diet therapy. At the initial visit all patients were advised to take a 'prudent' diet, containing approximately $50 \%$ carbohydrate, low saturated fat and moderately high fibre with a reduced energy content if obese, aiming to attain ideal body weight. For the first 3 months they were seen at monthly intervals, usually by a dietitian as well as a doctor.

Randomisations after 3 months' diet. After the initial 3 months on diet alone, three fasting plasma glucose estimations were taken for the therapy decision. Patients entered one of three main categories according to whether the mean of these fasting plasma glucose values was $\leq 6 \mathrm{mmol} / \mathrm{l}$ (diet satisfactory), $\geq 15 \mathrm{mmol} / \mathrm{l}$ (primary diet failure) or in between (main randomisation) (Fig. 3). In each there was a stratification for obesity (body weight $\geq 120 \%$ ideal body weight) [59]. Randomisation of patients was computer generated with allocations in sealed opaque envelopes, with a check maintained on numerical sequence, dates of opening and results. Subsequently patients were seen at 3-month intervals or more frequently if required. All patients continued to receive dietary advice.

(i) Main randomisation. If the mean of the three fasting plasma glucoselevels was $>6$ and $\leq 15 \mathrm{mmol} / 1$ the patients were allocated either to diet policy, in which the plasma glucose usually remained raised, or to active policy aiming for near-normal fasting plasma glucose, $<6 \mathrm{mmol} / 1$. In non-obese subjects the randomisation proportions were $30 \%$ to diet, $30 \%$ to insulin, $40 \%$ to sulphonylurea. Obese subjects were similarly randomised with an additional possibility of receiving metformin ( $24 \%$ to diet, $24 \%$ to insulin, $32 \%$ to sulphonylurea, $20 \%$ to metformin). Therapy allocations are shown in Table 2.

(ii) Primary diet failure. During the initial 3 months on diet, if either the fasting plasma glucose remained $>15 \mathrm{mmol} / \mathrm{l}$ or diabetic symptoms persisted, a separate randomisation was made allocating patients to active therapy only in the same proportions ( $44 \%$ to insulin, $56 \%$ to sulphonylurea in non-obese subjects and $32 \%$ to insulin, $42 \%$ to sulphonylurea and $26 \%$ to metformin in obese subjects).

(iii) Diet satisfactory with possibility of a delayed randomisation. If, after the initial 3 months on diet, the fasting plasma glucose fell to $\leq 6 \mathrm{mmol} / \mathrm{l}$, the patient was deemed diet satisfactory and main tained on diet alone. In $69 \%$ of patients the fasting plasma glucose subsequently increased to $>6 \mathrm{mmol} / \mathrm{l}$, and a separate delayed ran- 


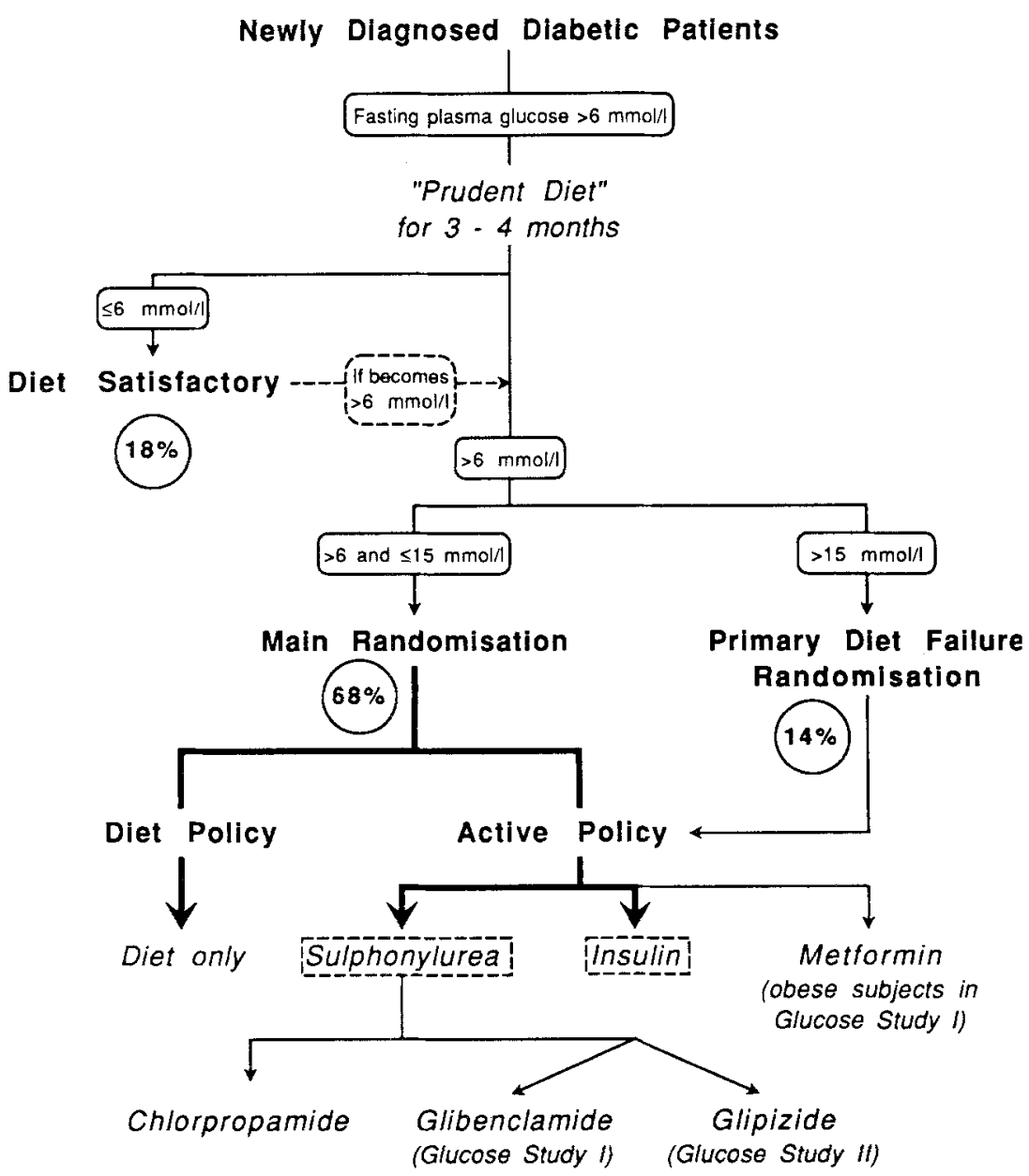

Fig.3. Outline of the UK Prospective Diabetes Study (UKPDS) domisation was made (at the end of the first year or at any other time thereafter) when the mean of three consecutive quarterly fasting plasma glucoses became $>6 \mathrm{mmol} / \mathrm{l}$. The therapy allocations were identical to the main randomisation group.

\section{Active policy regimens}

Insulin therapy. Patients randomised to insulin were started on ultralente (Ultratard HM, Novo, Copenhagen, Denmark), the initial dose being calculated from the fasting plasma glucose in $(\mathrm{mmol} / \mathrm{l}-3) \times 2$, to give the dose in units/day (IU) with an increase to $\mathrm{IU} \times(2.5 \times$ actual weight/ideal weight -1.5$)$ if the patient was obese [60]. A "normal" 'prudent' diet was advised, but no specific rules on the size or timing of meals was given as usually required with short-acting insulin therapy. Patients were provided with disposable insulin syringes and seen at one or two weekly intervals when the insulin dose was adjusted until the fasting plasma glucose became $\leq 6 \mathrm{mmol} / 1$. Patients requiring more than $12 \mathrm{IU} /$ day ultralente insulin were asked to monitor their blood glucose at home. If the pre-meal or pre-bedtime blood glucose concentrations were $>7 \mathrm{mmol} / \mathrm{l}$, soluble insulin (Actrapid HM, Novo or Humulin S, Eli Lilly, Indianapolis, Ind., USA) was added to their regimen [61], although other insulins could be used if glucose control was not satisfactory.

\section{Oral hypoglycaemic agents}

(i) Glucose Study I. Half the patients randomised to sulphonylurea therapy were allocated to chlorpropamide (maximum $500 \mathrm{mg}$ daily) and half to glibenclamide (maximum $10 \mathrm{mg}$ twice daily). The maxi- mum metformin dose was $1700 \mathrm{mg}$ at breakfast and $850 \mathrm{mg}$ at the evening meal.

Doses were increased at approximately 2 -week intervals, until the fasting plasma glucose was reduced to $<6 \mathrm{mmol} / \mathrm{l}$. Until 1989, monotherapy was used if feasible but when maximal sulphonylurea doses were given and either the fasting plasma glucose rose to $>15 \mathrm{mmol} / \mathrm{l}$ or symptoms developed, metformin was then added. From 1990 an amendment was made to maintain improved blood glucose control for a longer time in sulphonylurea-allocated patients who developed fasting plasma glucose $>6 \mathrm{mmol} / \mathrm{l}$ on the maximal dose [62]. The patients were randomly allocated, half to the addition of metformin aiming for $<6 \mathrm{mmol} / \mathrm{l}$ while the other half continued on sulphonylurea alone until the fasting plasma glucose was elevated to $>15 \mathrm{mmol} / \mathrm{l}$ or symptoms developed. The continuation of monotherapy in half the patients allows study of the response to sulphonylurea alone and also provides a comparison group with which to determine the efficacy of addition of metformin.

If, in the absence of intercurrent illness, hyperglycaemic symptoms developed or the fasting plasma glucose on maximal sulphonylurea and metformin became $>15 \mathrm{mmol} / \mathrm{l}$, the patient was transferred to insulin therapy. Obese patients primarily randomised to metformin, whose blood glucose levels deteriorated by the same criteria, were given additional glibenclamide therapy before being transferred to insulin.

(ii) Glucose Study II. When eight new centres were started in 19871988 , the basic design and the proportion of the allocations were not changed except that metformin was not included. Two modifications were made to the sulphonylurea allocation group. Glipizide (maximum $20 \mathrm{mg}$ twice daily) was used instead of glibenclamide, with chlorpropamide continuing as the other sulphonylurea. Because many patients allocated to sulphonylurea alone did not maintain 
Table 3. Diabetic tissue damage at diagnosis of diabetes in patients recruited to UK Prospective Diabetes Study [64]

\begin{tabular}{lc}
\hline & Prevalence \\
\hline Retinopathy (>1 microaneurysm) & $21 \%$ \\
Abnormal ECG & $18 \%$ \\
Myocardial infarct & $2 \%$ \\
Angina pectoris & $3 \%$ \\
Intermittent claudication & $3 \%$ \\
Stroke/transient ischaemic attack & $1 \%$ \\
Absent foot pulses (2 or more) and/or ischaemic feet & $14 \%$ \\
Impaired reflexes and/or decreased vibration sense & $7 \%$ \\
\hline
\end{tabular}

fasting plasma glucose $<6.0 \mathrm{mmol} / \mathrm{l}$ on maximal doses, additional ultralente insulin was then added to provide improved glycaemic control and to assess the potential benefit of combined therapy.

\section{Diet policy regimen}

It patients randomised to diet policy subsequently reached the same criteria as for primary diet failure, i. e. in the absence of intercurrent illness the fasting plasma glucose was $>15 \mathrm{mmol} / \mathrm{l}$ or symptoms de- veloped, they were classified as secondary diet failure and randomised to alternative therapies in the same proportions as primary diet failure. However, in keeping with the previous diet policy allocation in which patients usually continued to have fasting hyperglycaemia, the general guidelines for control with the additional therapy were to prevent symptoms and maintain fasting plasma glucose $<15 \mathrm{mmol} / 1$. The individual physicians were asked to use their normal approach for non-trial patients, and could decide whether to aim only for $<15 \mathrm{mmol} / \mathrm{l}$ or to aim for more strict control by increasing the dose of the therapy allocated at the secondary diet failure randomisation.

\section{Progress of glucose study}

Patient characteristics. At the termination of entry to the study in March 1991, 5100 patients had been recruited. The following data describe the population of 4072 patients ( $82 \%$ white Caucasian, $9 \%$ Afro-Caribbean, $8 \%$ Asian and $1 \%$ from other ethnic groups) recruited in 15 centres in Glucose Study I. The median age was 53 years, with a male preponderance of $59 \%$ at all ages [63]. The male subjects were not as obese as the females, (median weight $122 \%$ and $143 \%$ ideal body weight [59] respectively). The median fasting plasma glucose at presentation was $11.3 \mathrm{mmol} / \mathrm{l}$. Patients at all ages had, on average, a similar degree of obesity and a similar fasting plasma glucose. Fifty-five percent of patients presented with symptoms such as thirst and/or loss of weight; $30 \%$ because of hyperglycaemia found on routine testing; $13 \%$ with infections in-

Table 4. Clinical endpoints occurring in UK Prospective Diabetes Study. 994 endpoints or events occurred in 728 patients by March 1991

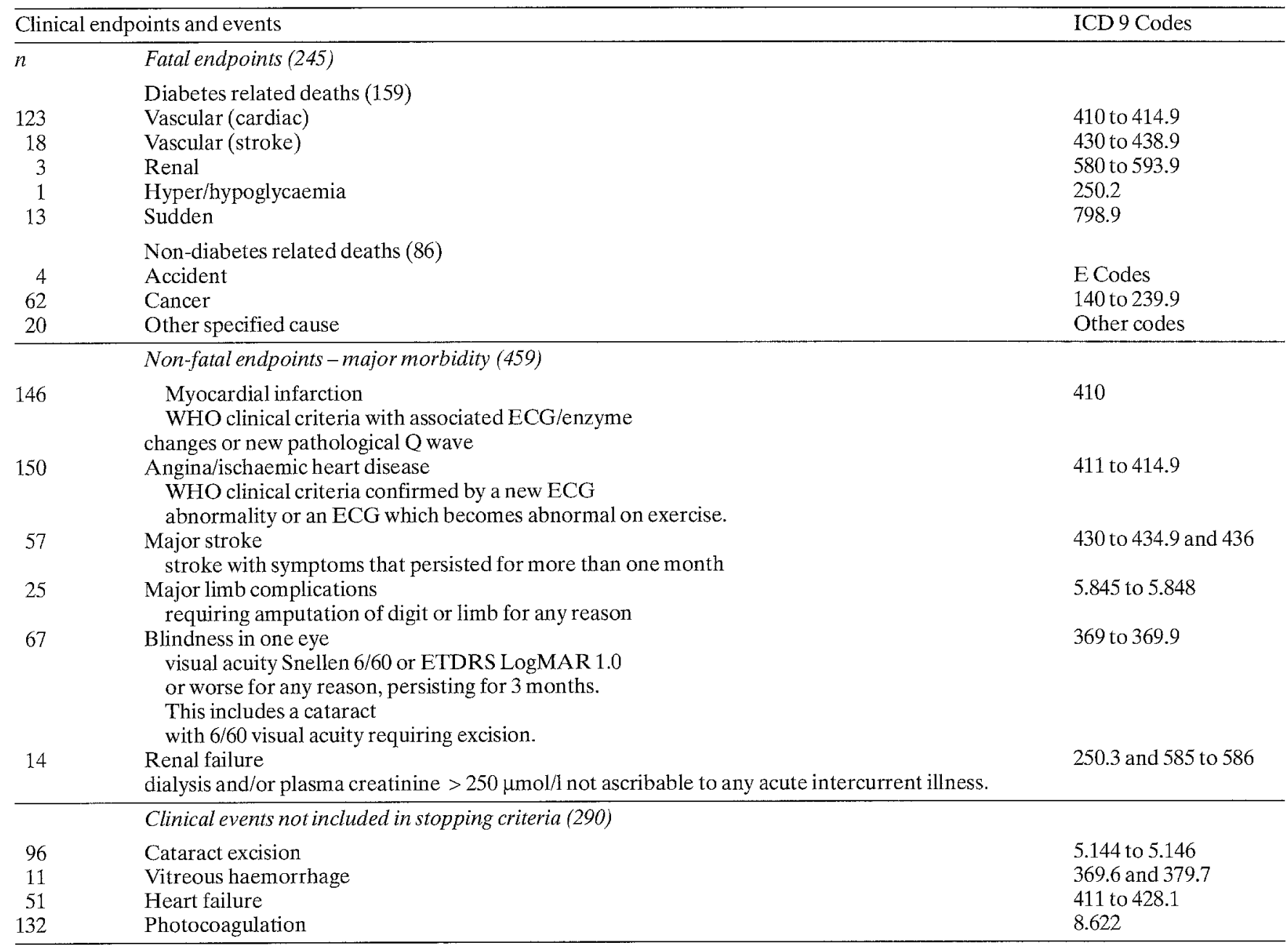


cluding balanitis and $2 \%$ because of a complication of infection. Approximately half the patients already had some evidence of diabetic tissue damage at entry into the study [64] (Table 3).

Efficacy of treatment regimens. Allocated therapies in main randomisation. The first 3000 patients recruited to the study have been followed for 3 years, 1969 entered the main randomisation while 1031 patients were either diet satisfactory or primary diet failure (Fig. 3). Figure 4 shows the fasting plasma glucose, haemoglobin $A_{1 c}$ $\left(\mathrm{Hb} \mathrm{A}_{i \mathrm{c}}\right)$ and body mass index according to the allocated therapies in those who were followed for 3 years in the main randomisation. The median fasting plasma glucose levels at therapy decision were similar, being $8.1,8.2$ and $8.3 \mathrm{mmol} / \mathrm{l}$ in the patients subsequently allocated to diet, sulphonylurea and insulin therapy respectively. Both the allocation to sulphonylurea and insulin significantly reduced the fasting plasma glucose, the median values over 3 years being $8.9 \mathrm{mmol} / \mathrm{l}$ on diet policy, $7.0 \mathrm{mmol} / \mathrm{l}$ on sulphonylurea $(p<0.001$ vs diet) and $7.0 \mathrm{mmol} / \mathrm{l}$ on insulin ( $p<0.001 \mathrm{vs} \mathrm{diet).} \mathrm{The} \mathrm{HbA}_{\mathrm{lc}}$ median value over 3 years was also higher on diet policy being $7.2 \%$ compared with $6.2 \%$ on sulphonylurea $(p<0.001)$ and $6.6 \%$ on insulin $(p<0.001)$ (initial values at therapy decision were $6.9 \%, 7.0 \%$ and $7.1 \%$ for the diet, sulphonylurea and insulin-treated patients respectively). The $\mathrm{HbA}_{1 \mathrm{c}}$ reduction was proportionately less than the decrease in fasting plasma glucose, as the post prandial plasma glucose excursions are less affected by therapies with a basal insulin supplement or sulphonylurea (Fig. 2). Body mass index did not markedly differ between the different allocation groups.

Adherence to protocol. By 3 years, 2741 (91\%) of the initial 3000 patients were still attending the clinics and had data available. Of these $4 \%$ had died and $5 \%$ were lost to regular follow-up although many of those without data still lived locally and will be subsequently contacted for annual or triennial reviews. In the main randomisation, by 3 years $83 \%$ of those allocated to insulin and $90 \%$ of those allocated to sulphonylurea were on the allocated therapy. Of those allocated to diet policy $30 \%$ had to be randomised as having secondary diet failure, either because fasting plasma glucose was $>15 \mathrm{mmol} / \mathrm{l}$ or because of symptoms due to hyperglycaemia.

\section{Blood pressure control study - Hypertension in Diabetes Study (HDS)}

The HDS was started in 1987 in 20 centres and in July 1991 included 1060 patients. It is planned to terminate the study in 1994 with a median 5-year follow-up.

\section{Study Design}

In the HDS two different levels of blood pressure (BP) control were compared by random allocation of hypertensive patients either to tight control (aiming for systolic $<150 \mathrm{~mm} \mathrm{Hg}$ and diastolic $<85 \mathrm{~mm} \mathrm{Hg}$ ) or to less tight control policy (aiming for systolic $<200$ and diastolic $<105 \mathrm{~mm} \mathrm{Hg}$ ). ACE inhibitor and Beta-blocker therapy were compared in the tight control group by random allocation to either captopril or atenolol.

Selection criteria. All hypertensive patients in the UKPDS were considered with the exclusion of patients who required strict blood pressure control due to a previous stroke, accelerated hypertension, cardiac or renal failure, patients who required Beta-blockade (myocardial infarction in the previous year, current angina) or already had severe vascular disease (more than one major vascular episode), patients in whom Beta-blockade was contraindicated (asthma, intermittent claudication, foot ulcers or amputations) and patients with a severe concurrent illness. The BP was measured by a trained nurse, with the patient in a sitting position, after at least 5 min rest with the forearm semi-flexed supported on a pillow with the palm facing upwards. The BP was routinely measured with a Copal UA-251 or a Takeda UA-751 electronic, automatic, ausculta- tory BP reading machine (Andrew Stephens Co., Brighouse, West Yorkshire, UK) but in obese arms with circumference $>33 \mathrm{~cm}$ it was measured with a Hawksley random zero sphygmomanometer (Hawksley \& Sons Ltd., Lancing, Sussex, UK) [65] with a large cuff. A Hawksley was also used in patients with atrial fibrillation. Diastolic BP was taken at the Korotkoff phase 5. In each patient, four consecutive readings were taken with intervals of at least 2 -min and the first reading was discarded while the mean of the last three readings was used in the study.

Patients could be either on no therapy or already on therapy for hypertension. They were included in the study if the mean of BP readings from three consecutive visits when not on therapy was
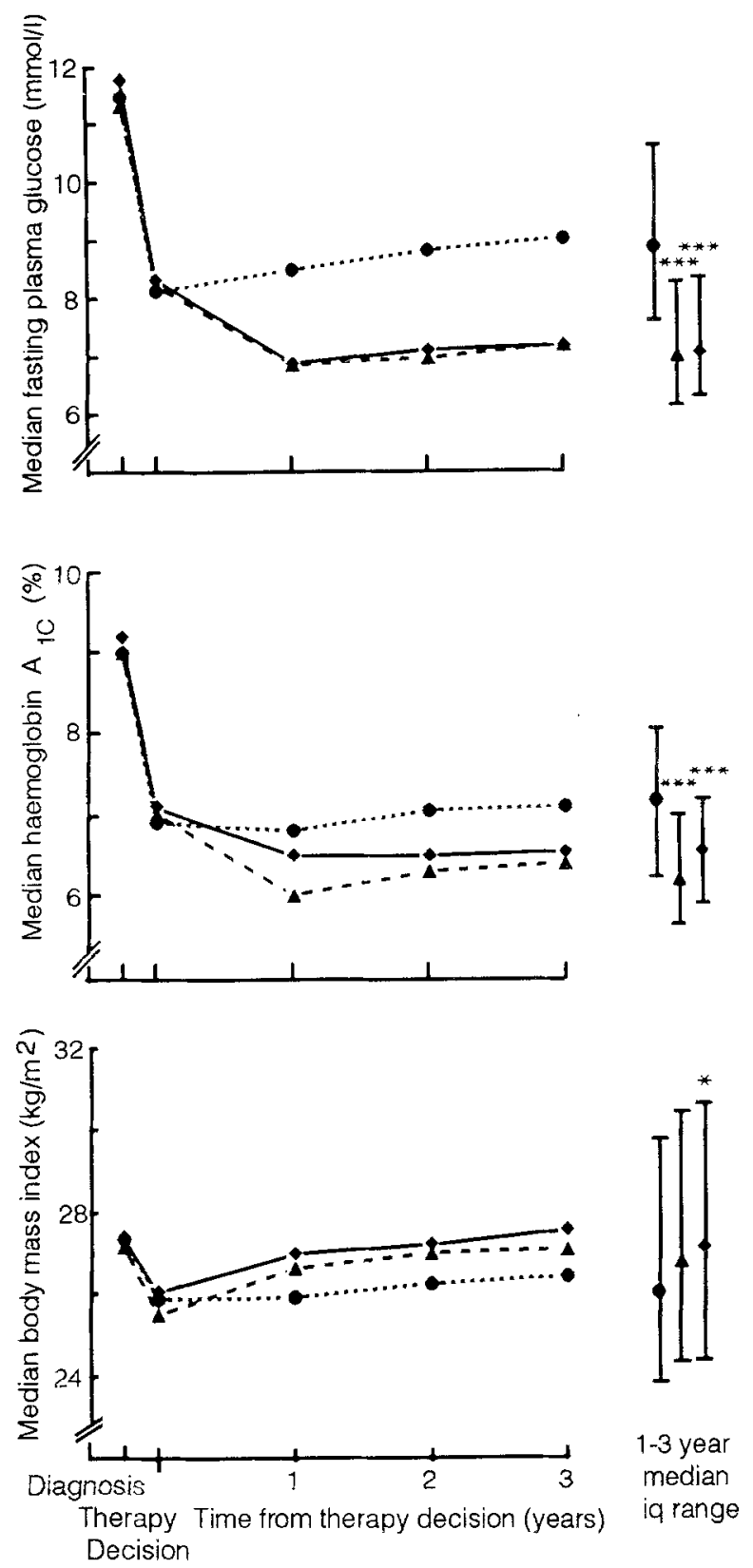

Fig. 4. Median fasting plasma glucose (upper panel), haemoglobin $\mathrm{A}_{1 c}$ (middle panel) and body mass index (lower panel) in main randomisation patients in UKPDS Glucose Study I over 3 years in patients allocated to diet policy $(\cdots \cdots, n=459)$ and active therapies (- insulin, $n=506, \cdots \wedge$ sulphonylurea, $n=638$ ). Vertical bars on the right show 1-3 year median and interquartile (iq) ranges for each randomisation group $(* * * * 0<0.001, * p<0.05$ for each active therapy vs diet policy) 


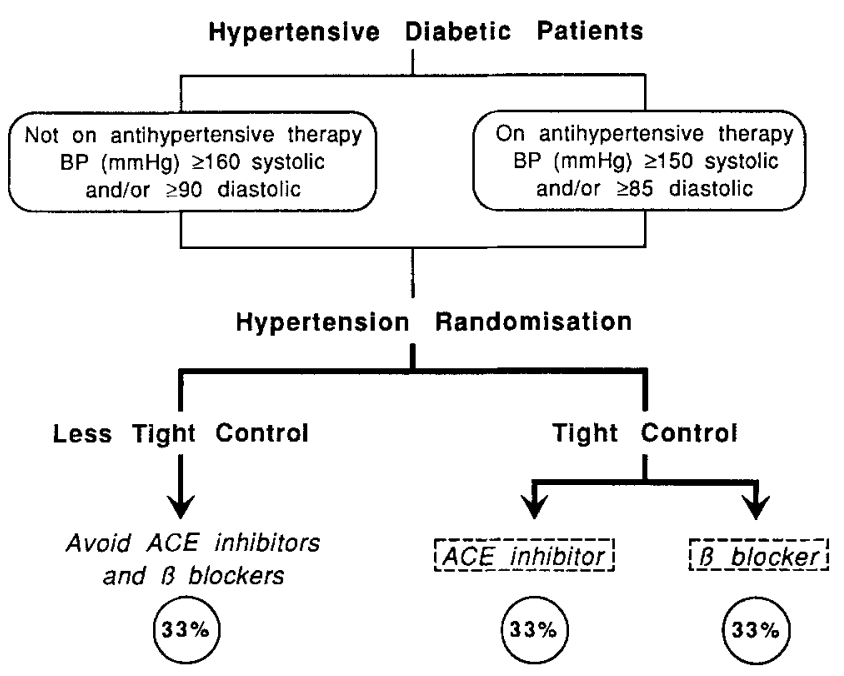

Fig.5. Outline of the Hypertension in Diabetes Study (HDS). BP = blood pressure, $\mathrm{ACE}=$ angiotensin-converting enzyme

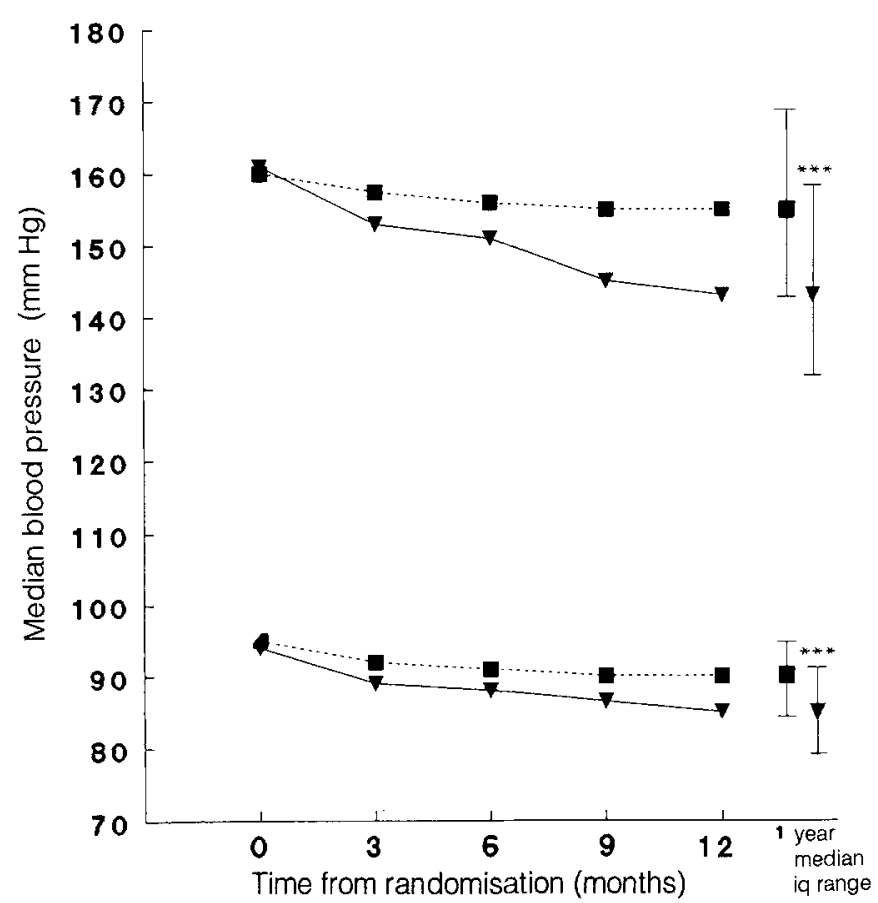

Fig. 6. Median blood pressure, systolic above and diastolic below, in patients in the Hypertension in Diabetes Study (HDS) over 1 year in patients allocated to less tight control $(\cdots \square, n=198)$ and tight control $(-\nabla-, n=386)$. Vertical bars on the right show median and interquartile (iq) ranges at 12 months for the randomisation groups (**** $p<0.001$ between the groups)

$\geq 160 \mathrm{and} / \mathrm{or} \geq 90 \mathrm{mmHg}$ or when on therapy was $\geq 150 \mathrm{and} / \mathrm{or}$ $\geq 85 \mathrm{~mm} \mathrm{Hg}$ (Fig. 5). In practice, if BP was raised on two consecutive visits, an additional appointment was made for the third series of readings. In treated patients with $\mathrm{BP}$ values below $150 / 85 \mathrm{~mm} \mathrm{Hg}$, hypotensive therapy could be reduced or stopped. The patients whose $\mathrm{BP}$ then rose to above the inclusion criteria were randomised in the study. If on any single occasion the BP was $\geq 200$ and/or $\geq 105 \mathrm{~mm} \mathrm{Hg}$, randomisation to tight or less tight control could be instituted.

Randomisations. Tight control of BP aiming for $<150 / 85 \mathrm{~mm} \mathrm{Hg}$ was allocated to $66.6 \%$ of the patients. Half of these were ran- domised to primary treatment with an $\mathrm{ACE}$ inhibitor, captopril and the other half to primary treatment with a Beta-blocker, atenolol. Less tight control of BP aiming for $<200 / 105 \mathrm{~mm} \mathrm{Hg}$ was allocated to $33.3 \%$ of the patients, which could often be achieved without drug therapy.

Tight control policy regimen. If a patient was already on a non-allocated primary therapy for BP control, this was stopped if feasible. The allocated therapy was usually started with captopril $25 \mathrm{mg}$ twice daily or atenolol $50 \mathrm{mg}$ once daily. If the patient allocated to captopril was already treated with a diuretic, this was stopped at least $24 \mathrm{~h}$ before captopril was introduced at a dose of $6.25 \mathrm{mg}$, the first dose being given in hospital with a 6 -h observation period. If the BP remained $\geq 150$ and/or $\geq 85 \mathrm{~mm} \mathrm{Hg}$ on a single reading, the dose was increased to the maximum of atenolol $100 \mathrm{mg}$ daily or captopril $50 \mathrm{mg}$ twice daily with other drugs (frusemide, long-acting nifedipine, methyldopa, prazosin) being added in sequence until the target control criteria were met. Physicians could use their clinical judgement on choice of therapies, e.g. if symptoms occurred on any drug, the therapy could be changed accordingly.

Less tight control policy regimen. At the randomisation of treatment, if a patient was already being treated with an ACE inhibitor or a Beta-blocker, this was stopped if feasible. If the BP remained at or became $\geq 200 \mathrm{and} / \mathrm{or} \geq 105 \mathrm{~mm} \mathrm{Hg}$, other drugs (frusemide, nifedipine, methyldopa, prazosin) were given sequentially, until the target control criteria were met. If possible, ACE inhibitors and Betablockers were not used.

\section{Progress of hypertension study}

Characteristics of patients. By July 1991, 1060 patients (median age 58 years, $55 \%$ males) had been recruited. Median BP at entry into the HDS was $158 / 94$ in men and $162 / 92 \mathrm{~mm} \mathrm{Hg}$ in women. Antihypertensive treatment was already being used for $34 \%$ of the men and $43 \%$ of the women.

Efficacy of treatment regimens. Data are presented for the initial 584 patients recruited and followed-up for 1 year (Fig. 6). Both the allocated ACE inhibitor and Beta-blocker similarly and significantly reduced the $\mathrm{BP}$. At one year the median $\mathrm{BP}$ in the patients allocated to tight BP control was $11 \mathrm{~mm} \mathrm{Hg}$ systolic and $5 \mathrm{~mm} \mathrm{Hg}$ diastolic lower than in the less tight control group.

Adherence to protocol. By one year $83 \%$ of those allocated to captopril and $84 \%$ of those allocated to atenolol were on the allocated therapies. Additional therapy was needed by $42 \%$ of ACE inhibitortreated and $59 \%$ of Beta-blocker-treated patients to maintain a BP $<150 / 85 \mathrm{~mm} \mathrm{Hg}$. Hypotensive therapy was being used for $50 \%$ of those allocated to less tight control, with only $14 \%$ being treated with ACE inhibitor or a Beta-blocker.

\section{General aspects of the studies}

Both studies received ethical approval from the appropriate committee in each centre. If during the trials any patients required strict blood glucose or blood pressure control for clinical reasons, therapy would then be adjusted as for non-trial patients. Each of the 23 centres cared for patients in special UKPDS clinics which were staffed by doctors and nurses funded by the UKPDS. Clinics were held in the morning.

Patients came fasting to each clinic and routine therapy was governed by the fasting plasma glucose, BP and body weight which were measured at the clinic visit. Strict guidelines for managing each randomisation allocation were provided in the clinic including a laminated sheet for easy reference. The patients' notes had colour-coded dividers, one for the glucose study and one for the hypertension study, giving instructions pertaining to the allocated therapy for that patient.

Patients were seen either at 3-month intervals or more frequently if interim adjustment of blood glucose or $\mathrm{BP}$ therapy was required to 
attain the control criteria. A detailed data sheet was completed at each quarterly visit. One section addressed diabetic control with details of actual therapy and doses, home blood glucose monitoring and hypoglycaemic episodes. A hypertension section noted the type and doses of hypotensive drugs taken. A section on general health noted illness, time off work and general symptoms including any side effects of drugs. All hospital admissions were indicated and details obtained and kept at the co-ordinating centre.

Annual clinical assessment. Every 12 months an additonal check list was completed to determine whether any clinical events which might count as study endpoints had occurred. The visual acuity was assessed for blindness (Snellen $\leq 6 / 60$ or LogMAR $\geq 1.0$ on ETDRS chart [66]).

Triennial clinical assessment. At entry and at 3-year intervals thereafter, all patients received a full clinical examination. Retinal colour photography of four fields per eye (nasal, disc, macula and temporal to macula fields) were taken in duplicate with $30^{\circ}$ cameras, with stereo photographs of the macula. The photographs were assessed at a grading centre for quality, and repeat photographs taken if necessary. They were assessed by two independent assessors. If there was evidence of diabetic retinopathy by the criteria used for the the Diabetes Control and Complications Trial (DCCT) [30] the fields were graded by a further two independent assessors using a modified "191" grading system [67]. Ophthalmic assessment was made in the clinic by direct or indirect ophthalmoscopy. Visual acuity has been measured since 1989 with an ETDRS chart [66] and previously with Snellen charts. Neuropathy was assessed clinically by knee and ankle reflexes and biothesiometer (Biomedical Instruments $\mathrm{Co}$., Newbury, Ohio, USA) readings were taken from the lateral malleoli and the end of the halluces [68]. Autonomic neuropathy was assessed by measurement of the $R-R$ variation in response to deep breathing [69] and to standing [70]. A chest X-ray was taken to assess the cardiac diameter and a 12-lead ECG for subsequent Minnesota coding [71]. Doppler BP was measured in both legs and in the right arm.

Additional therapy. All patients continued to receive dietary advice throughout the study and were encouraged to give up smoking. Regular aspirin therapy was not advised, unless there was a specific indication such as a recent myocardial infarction. Centres were notified if the total cholesterol or triglyceride values were greater than 8.5 or $4.0 \mathrm{mmol} / \mathrm{l}$ respectively and could institute hypolipidaemic therapy if dietary advice failed to lower these values satisfactorily.

Biochemistry. The fasting plasma glucose was measured in each centre at each patient visit. For other assays, fasting blood and random urine samples were taken at diagnosis, therapy decision, 6 months, 1 year and annually thereafter. Fasting blood samples were taken for $\mathrm{HbA}_{1 \mathrm{c}}$, plasma creatinine, urate, triglyceride, total cholesterol, LDL- and HDL-cholesterol, $\mathrm{N}$-acetyl-glucosaminidase (NAGase), immuno-reactive insulin and insulin antibodies [72-77]. Urine samples for albumin, creatinine and NAGase measurement were taken [78-81]. Plasma creatinine and urate were measured in each centre while other biochemical measurements were made at the co-ordinating centre. Blood and urine samples were sent to $\mathrm{Ox}$ ford by an overnight delivery service in boxes kept at $4^{\circ} \mathrm{C}$. $\mathrm{HbA}_{1 \mathrm{c}}$ values for patients allocated to active policy were sent to centres, to alert them when the levels were $>6 \%$ (normal range $4.2-6.1 \%$ ).

Quality assurance. Plasma glucose assays. Glucose measurements were monitored by a quality control scheme in which four quality control samples were sent from the co-ordinating centre to each centre each month for measurement with the patients' samples. A statistical analysis of the monthly results was sent to each centre. Any result outside 3 SD from the mean was excluded from the final analysis and reasons for such discrepancies were investigated. Summary statistics were compiled at 6-month intervals giving the mean for each quality control material. In the last six months' data, a sample with a glucose value of $8.1 \mathrm{mmol} / \mathrm{l}$ from the UK External Quality Assessment Scheme (UKEQAS) read a mean of $8.0 \mathrm{mmol} / \mathrm{l}$ in the UKPDS centres. The mean percentage bias for each centre ranged from $-5.4 \%$ to $+5.2 \%$. Statistics on internal quality control in each centre were also obtained.

Other biochemical assays. Assays were monitored by a computerised quality control scheme using tri-level quality control sera. Westgard rules [82] were applied for acceptance of results. A monthly quality control report was prepared with data on coefficient of variation, bias, drift and assay rejection rate. Assays were monitored by external quality control schemes where possible (UKEQAS and Wellcome).

Blood pressure measurements. Every month, BP readings with the electronic sphygmomanometers were compared with a simultaneous measurement with a Hawksley sphygmomanometer.

\section{Quality of life study}

The eight Glucose Study II centres conducted a quality of life study. Assessment was based on a questionnaire especially adapted for the UKPDS which was completed by patients at defined intervals. The questionnaires were completed in a quiet room, with no help from the nursing staff or from family members. In addition, first degree relatives or companions completed a short questionnaire to establish whether patients' views of themselves differed from those of people who knew them well. The Glucose Study I centres administered the questionnaire on one occasion in a cross-sectional study.

\section{Communication between centres and data handling}

Practical aspects and various analyses were discussed in the twice yearly meetings between the centres which were held in Oxford. As well as plenary sessions, doctors, nurses, dietitians and retinal photographers had their separate sessions. The performance of individual centres, e.g., recruitment, plasma glucose or blood pressure control, was openly discussed. A separate meeting of nurses was held once per year, to discuss all administrative aspects and the techniques for assessing endpoints. Centres telephoned direct to the co-ordinating office with any protocol queries. Every week a package was sent to each centre with supplies, letters or other information.

\section{Database management system}

The main database was kept on a personal computer (Olivetti M380 with $210 \mathrm{Mb}$ hard disk). The system used dBase III with Clipper and consisted of a number of linked database files and programs to control entry of data, validation of data items, editing of corrected data and compilation of quality control and progress-chasing statistics, as well as data extraction for analysis. The programs issued colourcoded letters to the centres with queries about anomalies, missing data or values outside expected limits.

Clinical data from each patient's visit were entered in boxes on data sheets on which provision was made for hand-written comments. Photocopies were sent to the co-ordinating centre and were processed through a double-entry key-to-disk system to generate a file which was validated by range checks, combinatorial checks and historical checks relating to compatibility with previous data. A listing of anomalies was read by trained staff against the information contained in the data sheets, all of which were visually checked. Anomalies which could not be explained were notified to the centres for their assistance in completing or correcting the data. Only when all data had been checked and validated were they entered into the main database.

The programs also checked the recently added fasting plasma glucose and $\mathrm{BP}$ values and the data from the previous visits, so that letters could be produced alerting physicians of the possible need to amend therapy at the next visit or of a potential randomisation if control criteria were not being attained. For the retinal photography a similar system of database and control programs checked and 
Table 5. Stopping criteria for UK Prospective Diabetes Study and the Hypertension in Diabetes Study

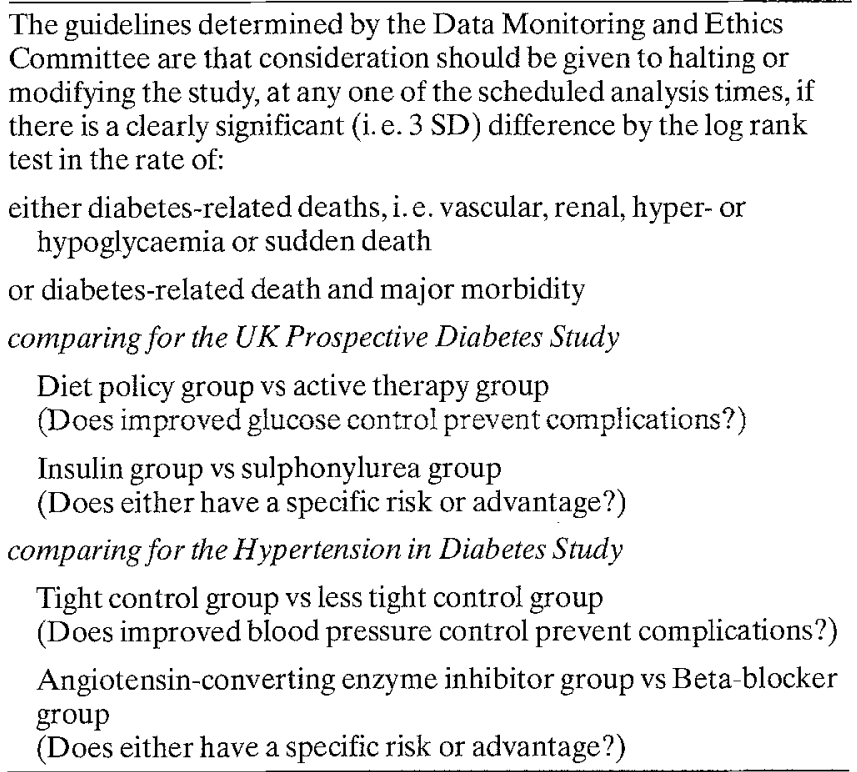

stored the data from the ' 191 ' grading of retinal photographs and generated the final code.

At monthly intervals each centre was sent a letter indicating overdue items such as data sheets, ECGs, retinal photographs and biochemical samples in order to minimise loss of data.

Data for analysis was extracted from the main database and transferred to the Oxford University Computing Service VAX cluster for analysis using the SAS computer program as the main statisti$\mathrm{cal}$ analysis system. Data security was maintained by exclusion of patient identities, the provision of password access and secure printer and plotter output within the co-ordinating centre.

\section{Endpoints}

\section{Major endpoints}

In 1981 two combinations of endpoints were chosen to be used as stopping criteria for the study in order to reduce the number of treatment comparisons and thus diminish the chance of a false positive treatment difference emerging. The groupings are shown in Tables 4 and 5.

Endpoint validation. Possible clinical endpoints were officially noted on the annual visit data sheets or were detected by the administrator or clinical staff from written comments on the quarterly visit data sheets. Patients in England and Wales were flagged on the Central Office of Population Censuses and Surveys computer which notifies when a patient has been certified dead. Patients in Scotland and Northern Ireland were similarly identified in the relevant offices. The diagnostic criteria for each endpoint were pre-determined. When an endpoint was notified on a data sheet, the administrator requested full information from the notifying centre and it was formally presented (separate from the routine clinical details) to two clinical assessors. The two separate assessments for each endpoint were entered onto special data sheets. If there was disagreement on the assessment, the informa- tion was submitted to two further independent assessors for final decision. All information about each endpoint was filed to provide full documentation if necessary. The International Classification of Diseases (9th revision) was used [83], which subsume into the categories shown in Table 4 .

Statistical analysis and criteria for stopping or modifying the study. All major analyses are according to assigned allocations (intention to treat), without exclusion of protocol deviants. In the Glucose Study, the major comparison is in the combined main randomisation and delayed randomisation groups between those allocated to diet policy and those allocated to active policy (i. e. to insulin or to sulphonylurea) to assess whether improved glycaemic control prevents complications. A subsidiary comparison is between those allocated to insulin and those allocated to sulphonylurea in all the randomisation groups to assess whether either has a specific risk or advantage. These primary comparisons, which are done without subgroup analysis, are statistically independent from each other (Table 5). The response to metformin therapy in the obese subjects is assessed by comparison with those allocated to diet policy and to sulphonylurea therapy.

In the Hypertension Study the main comparison is between the tight control group and the less tight control group. A subsidiary comparison is between those allocated to Beta-blocker and those allocated to ACE inhibitor therapy. The same stopping criteria as for the Glucose Control Study are used, except that hypertension-related deaths exclude hyper- and hypoglycaemia.

The blood glucose and the blood pressure study are examined separately and independently. The Data Monitoring and Ethics Committee has examined endpoints annually and will determine when the totality of currently available evidence indicates either a study should be terminated or the balance of advantage and disadvantage of certain treatments is such that the management of some category of patients in the study should be altered (Table 5).

\section{Surrogate endpoints}

Surrogate endpoints are sub-clinical indices of diabetic tissue damage. Nephropathy was assessed by the albumin/creatinine ratio and the $\mathrm{N}$-acetylglucosaminidase/creatinine ratio on random clinic urine samples and by plasma creatinine; retinopathy by colour retinal photographs with modified " 191 " grading; heart disease by ECG with Minnesota coding; peripheral neuropathy by biothesiometer readings of vibration perception threshold and autonomic neuropathy by the RR interval on deep breathing and standing.

\section{Progress of endpoints}

Clinical endpoints. Table 4 shows the endpoints which had occurred by March 1991. The numbers obtained agree with the initial empirical observation in 1984 of approximately $0.8 \%$ per annum diabetes-related deaths and 
Table 6. Estimated power of studies

\begin{tabular}{|c|c|c|c|}
\hline \multirow[t]{2}{*}{ Major analyses } & \multirow{2}{*}{$\begin{array}{l}\text { Incidence of first } \\
\text { major clinical } \\
\text { endpoint (per } \\
100 \text { patients per } \\
\text { annum) }\end{array}$} & \multicolumn{2}{|c|}{$\begin{array}{l}\text { Likelihood of detecting an advan- } \\
\text { tage to improved control at } p<0.05 \\
\text { Advantage to improved control }\end{array}$} \\
\hline & & $\begin{array}{l}20 \% \\
\text { advantage }\end{array}$ & $\begin{array}{l}25 \% \\
\text { advantage }\end{array}$ \\
\hline $\begin{array}{l}\text { Blood glucose } \\
\text { study } \\
\text { Diet policy vs } \\
\text { active policy }\end{array}$ & 2.8 & $91 \%$ & $99 \%$ \\
\hline $\begin{array}{l}\text { Blood pressure } \\
\text { study } \\
\text { Less tight control } \\
\text { vs tight control }\end{array}$ & 4.8 & $50 \%$ & $71 \%$ \\
\hline
\end{tabular}

$2.8 \%$ per annum diabetes-related deaths or major morbidity. Prior to 1987, patients with hypertension by WHO criteria at diagnosis had $70 \%$ more endpoints than nonhypertensive subjects.

Surrogate endpoints. The microalbuminuria and retinopathy might be particularly informative in view of the data suggesting a glycaemic threshold in the region of a fasting plasma glucose of $7.8 \mathrm{mmol} / \mathrm{l}$. Over the initial 3 years in the main randomisation, $67 \%$ of active policy patients had fasting plasma glucose below this value whereas $70 \%$ of diet policy patients had a fasting plasma glucose above this putative threshold. Both of these surrogate endpoints showed progression of diabetic tissue damage during the study in patients allocated to diet policy. Over 3 years, the number of patients having microalbuminuria greater than $2.5 \mathrm{~g} / \mathrm{mol}$ albumin/creatinine increased from $17 \%$ to $22 \%$ and the number having moderately severe retinopathy (' 191 ' grade 31,31 or worse) increased from $8 \%$ to $15 \%$.

Power of the study. Table 6 gives the likelihood of detecting a $20 \%$ or $25 \%$ reduction of endpoints by improved plasma glucose and blood pressure control. This reduction has been accepted as being a clinically significant gain, particularly as benefits from treatment are likely to be even greater over a longer period of therapy since complications develop over many years. Power calculations assumed $8 \%$ loss to follow-up and a $4 \%$ per annum increased number of events as the cohort ages.

\section{Discussion}

The UK Prospective Diabetes Study has the potential for determining whether improved blood glucose control will be beneficial in preventing complications. In patients with Type 2 diabetes it has the potential power to detect a $20 \%$ reduction of major diabetes-related clinical events which are mainly macrovascular in origin. It also has a good chance of determining whether improved glycaemic control will prevent microvascular disease in view of the high prevalence of retinopathy and microalbuminuria and their rate of deterioration. The majority of active policy patients attained glycaemic levels below those associated in epidemiological studies with the development of retinopathy and microalbuminuria. The study is 3.5 times larger than DCCT $[30]$ which was primarily designed to assess whether improved glucose control will reduce progress of indices of retinopathy, neuropathy and nephropathy in Type 1 diabetic patients. The DCCT and UKPDS are both expected to report in 1994 and are complementary studies.

The high prevalence of complications at presentation of Type 2 diabetes in middle age [64] suggests that the current organisation of health care is sub-optimal, since diabetes is often diagnosed only when it becomes symptomatic and tissue damage has often already occurred. If the study shows that improved glycaemic control will prevent complications, there will be a strong case for introducing regular screening of the population in middle age to detect diabetes before its complications ensue.

The study has shown that routine therapy of Type 2 diabetes with a basal insulin supplement is an effective and acceptable mode of therapy. It causes a similar rate of hypoglycaemic episodes as sulphonylurea and has no greater propensity to increase body weight [56]. The UKPDS will assess the relative benefits of sulphonylurea, insulin and metformin therapy in relation to diabetic complications. As this study is five times larger than the University Group Diabetic Program [27] any tendency for sulphonylurea to induce cardiac death should be refuted or confirmed. The study will provide comparative data on the efficacy of metformin and of insulin therapy in patients in whom basal normoglycaemia no longer was attained with maximal sulphonylurea therapy [62].

Several biochemical variables which might be relevant to microvascular or macrovascular disease are monitored at yearly intervals. Preliminary data from the Paris Prospective Study [26] and the UKPDS [64] suggest triglyceride may be a more important risk factor for cardiovascular disease in diabetic patients than in the general population. The routine measurement of triglyceride and of total, HDL- and LDL-cholesterol will allow assessment of the relative importance of these risk factors.

The study is both a primary and a secondary prevention trial. Thus it should be feasible to determine whether complications can be prevented in patients without any sign of complications, e.g. no microalbuminuria or retinopathy, and whether progression can be inhibited in those who already have microalbuminuria or retinopathy. Microalbuminuria is known to presage an increased risk of cardiovascular mortality [84-86] and in the UKPDS an association with an abnormal ECG has been found [64]. The study will be able to determine prospectively the degree to which patients with microvascular disease are at increased risk of cardiovascular events and whether improved blood glucose or blood pressure therapy will be particularly advantageous in this subgroup.

The greatly increased incidence of cardiovascular events in hypertensive compared with normotensive patients found in the UKPDS [87] raises the possibility that improved blood pressure control may be advantageous. The inclusion of the Hypertension in Diabetes Study in a factorial design allows assessment of hypotensive therapy in the cohort of patients studied, independently from the hypoglycaemic treatment. During the first year of followup both the allocated ACE inhibitor and Beta-blocker similarly and significantly reduced the blood pressure. The difference in blood pressure values between the tight 
control and the less tight control groups was similar to that obtained in studies of therapy of hypertension in the general population $[33,34]$. The blood glucose and the blood pressure studies will be examined statistically as completely different studies. They will allow a costbenefit analysis of the major hypoglycaemic therapies and of two frequently used therapies of hypertension.

\section{UK Prospective Diabetes Study Group}

\section{Co-ordinating centre}

Co-ordinator: R.C.Turner; Deputy Co-ordinators: R. R. Holman, D.R.Matthews; Administrator: P. A. Bassett; Deputy Administrator: L.R.Nolan; Statisticians: I.M.Stratton, C. A. Cull; Consultant Statistician: R. Peto; Research Associate: V.Frighi; Applications Programmer: I.A.Kennedy; Biochemist: S. E. Manley; Chief Medical Scientific Officer: E. G. Bown; Dietician: E. A. Eeley (Oxford); Consultant Biochemist: I. Ross (Aberdeen); Endpoint confirmation: D.R. Matthews (Oxford), T.L.Dornan (Salford), A.D.Wright (Birmingham); Retinal Photograph Grading Centre: E.M. Kohner, S. Aldington (Hammersmith); Minnesota Coding ECGs: A.H.Keen, C. Rose (Guy's Hospital); Quality of Life Questionnaire: A.E. Fletcher, C.Battersby (Hammersmith), J.S. Yudkin (Whittington). Previous participants: Administrator: S.F. Oakes; Statisticians: A. Smith, Z. Nugent; Deputy coordinator: J.I.Mann

\section{Clinical centres}

Physicians: R.C.Turner, R.R.Holman, M.R.Stearn, S.L.Palmer, M.S.Hammersley, S.L.Franklin, R.S. Spivey, D.T.Hockaday (Oxford); L.E.Murchison, A.H.E.Brunt, M.J.Williams, D.W.MacPearson, X.M.P.Petrie, M.E.J.Lean (Aberdeen); A.D.Wright, N.A.Levi, A.C. I.Shearer, R.J.W.Thompson (Birmingham); N.W. Oakley, M.A. Whitehead, G.P.Hollier, S. S. Nussey (St George's); E. M. Kohner, M. C. Doddridge (Hammersmith); J.R.Hayes, R.W.Henry, M.S. Fetherston (Belfast, City Hospital); L.Alexander, J.H.Scarpello, D.E. Shiers, R. J. Tucker, J.R.H. Worthington (Stokeon-Trent); D. R.Hadden, L.Kennedy, A.B.Atkinson, A.M.Culbert, C.Hegan (Belfast RVH); A.S.Spathis, M.E.Nanson, L.M.James, J.M. Tyrell (Carshalton); J.S. Yudkin, B.J.Gould, J.Singer, A. Badenock (Whittington); R.H.Greenwood, J.Wilson, M.J.Denholm, R.C.Temple (Norwich); L.J.Borthwick, D.J. Wheatcroft, R.J.Seaman, R. A.Christie (Stevenage); J.L.Day, M.J.Doshi, J.G.Wilson, J.R.Howard-Williams (Ipswich); R. W.Newton, R. T. Jung, C. Roxburgh, B. Kilgallan (Dundee); C. V.Fox, M.C. Holloway, H.M. Coghill (Northampton); R.B.Paisey, N.P.R.Brown, A.J.Tucker (Torbay); J.M.Roland, D.J.Brown, J. Youens (Peterborough); P.M.Brown, A.J.M.Davidson (Scarborough); I.D.A.Peacock, N.J.C.Culverwell, M.H.Charlton, B.P.S. Connolly (Derby); A.J. M.Boulton, A. M. Robertson (Manchester); R.J. Young, T.L.Dornan, J.R.Clyne
(Salford); A.C.Burden, E.M.Sellen (Leicester); J.E. Tooke (Exeter).

\section{Advisory groups}

Data Monitoring and Ethics Committee. W.J.H.Butterfield, W.R.S.Doll, K.McPherson, R.F.Mahler, T.W. Meade, D. G. Seigel, G. Shafer, P. J. Watkins

Policy Advisory Group. C.V.Fox, D.R.Hadden. R. R.Holman, D. R. Matthews, R. C. Turner, A. D. Wright, J.S. Yudkin

Steering Committee for Glucose Study I. K.G.M.M.Alberti, R.Denton, J.V.Forrester, R.R.Holman, P.D. Home, S.Howell, J.R.Jarrett, V.Marks, M.Marmot, R.C. Turner, J.D. Ward

Steering Committee for Hypertension in Diabetes Study. A.B.Atkinson, R. R.Holman, J.G.G.Ledingham, A.E.G. Raine, R.C.Turner

Acknowledgements. The cooperation of the patients and many National Health Service and non National Health Service staff at the centres is much appreciated. We are grateful to the Oxford Medical School Research Fund, the Charles Wolfson Charitable Trust, Clothworker's Foundation and the Alan and Babette Sainsbury Charitable Fund who gave grants for the pilot study. The Glucose Study I has been supported by grants from British Diabetic Association, Medical Research Council, National Eye Institute and National Institute of Digestive, Diabetes and Kidney Disease of the National Institutes of Health, USA, The Health Promotion Research Trust, Hoechst, Lilly, Novo-Nordisk and Lipha. The Hypertension Study and Glucose Study II have been supported by Bristol Myers Squibb and Farmitalia Carlo Erba. We are grateful for additional assistance from companies and charities including Becton Dickinson, Owen Mumford, Securicor Ltd., Boehringer Mannheim, Kodak, and Cortecs Diagnostics Ltd., and to Miss V. Summers who typed the manuscript.

\section{References}

1. Zimmet P (1982) Type 2 (non-insulin dependent) diabetes: an epidemiological overview. Diabetologia 22:399-411

2. Mather HM, Keen H (1985) The Southall Diabetes Survey: prevalence of known diabetes in Asians and Europeans. Br Med J 291: 1081-1084

3. Garcia MJ, McNamara PM, Gordon T, Kannell WB (1974) Morbidity and mortality in diabetics in the Framingham population. Sixteen year follow-up study. Diabetes 23: 105-111

4. Panzram G (1987) Mortality and survival in Type 2 (non-insulindependent) diabetes mellitus. Diabetologia 30: 123-131

5. Panzram G, Zabel-Langhennig R (1981) Prognosis of diabetes mellitus in a geographically defined population. Diabetologia 20: 587-591

6. Laing W, Williams DRR (1989) Diabetes, a model for health care management. Office of Health Economics, London UK, No 92: $32-49$

7. University Group Diabetes Program. Knatterud GL, Klimt CR, Levin ME, Jacobson ME, Goldner MG (1978) Effects of hypoglycaemic agents on vascular complications in patients with adult-onset diabetes. VII. Mortality and selected nonfatal events with insulin treatment. JAMA 240: 37-42

8. Jarrett RJ, Keen H (1976) Hyperglycaemia and diabetes mellitus. Lancet II: 1009-1012

9. Pettitt DJ, Knowler WC, Lisse JR, Bennett PH (1980) Development of retinopathy and proteinuria in relation to plasma glucose concentration in Pima Indians. Lancet II: 1050-1052 
10. Dornan TL, Mann JI, Turner RC (1982) Factors protective against retinopathy in insulin-dependent diabetics free of retinopathy for 30 years. Br Med J 285: 1073-1077

11. McCance DR, Hadden DR, Atkinson AB, Archer DB, Kennedy L (1989) Long-term glycaemic control and diabetic retinopathy. Lancet II: 824-828

12. Lauritzen T, Frost-Larsen K, Larsen HW, Deckert T and the Steno Study Group (1985) Two-year experience with continuous subcutaneous insulin infusion in relation to retinopathy and neuropathy. Diabetes 34 [Suppl 3]: 74-79

13. The Kroc Collaborative Study Group (1988) Diabetic retinopathy after two years of intensified insulin treatment. JAMA 260: $37-41$

14. Dahl-Jørgensen K, Brinchmann-Hansen O, Hanssen KF et al. (1986) Effect of mean normoglycaemia for two years on progression of early diabetic retinopathy, nephropathy and neuropathy; the Oslo Study. Br Med J 293: 1195-1199

15. Bilous RW, Mauer SM, Sutherland DE, Najarian JS, Goetz FC, Steffes MW (1989) The effects of pancreas transplantation on the glomerular structure of renal allographs in patients with insulin-dependent diabetes. N Engl J Med 321: $80-85$

16. Kennedy WR, Navarro X, Goetz FC, Sutherland DER, Najarian JS (1990) Effects of pancreatic transplantation on diabetic neuropathy, N Engl J Med 322: 1031-1037

17. Holman RR, Turner RC (1980) The basal plasma glucose: a simple, relevant index of maturity-onset diabetes. Clin Endocrinol 14:279-286

18. Howe-Davies S, Simpson RW, Turner RC (1980) Control of maturity-onset diabetes by monitoring fasting blood glucose and body weight. Diab Care 3: 607-610

19. Holman RR, Turner RC (1977) Diabetes: the quest for basal normoglycaemia. Lancet I: 469-474

20. WHO Study Group (1985) Diabetes mellitus. World Health Organisation Technical Report Series No 727. WHO, Geneva

21. Fuller JH, Shipley MJ, Rose G, Jarrett RJ, Keen H (1980) Coronary-heart disease risk and impaired glucose tolerance. The Whitehall study. Lancet I: $1373-1376$

22. Eschwège E, Richard JL, Thibult N et al. (1985) Coronary heart disease mortality in relation with diabetes, blood glucose and plasma insulin levels. The Paris Prospective Study, ten years later. Horm Metab Res [Suppl 15]: 41-46

23. Stamler R, Stamler J (1979) Asymptomatic hyperglycaemia and coronary heart disease. A series of papers by the International Collaborative Group based on studies in fifteen populations. $\mathbf{J}$ Chron Dis 32: 683-837

24. Fontbonne A, Charles MA, Thibult N et al. (1991) Hyperinsulinaemia as a predictor of coronary heart disease mortality in a healthy population: the Paris Prospective Study, 15 year followup. Diabetologia 34:356-361

25. Reaven GM (1988) Role of insulin resistance in human disease. Diabetes 37: 1595-1607

26. Fontbonne A, Eschwège E, Cambien F et al. (1989) Hypertriglyceridaemia as a risk factor of coronary heart disease mortality in subjects with impaired glucose tolerance or diabetes. Results from the 11-year follow-up of the Paris Prospective Study. Diabetologia 32: 300-304

27. University Group Diabetic Program (1970) A study of the effects of hypoglycaemic agents on vascular complications on patients with adult-onset diabetes II. Mortality results. Diabetes 19 [Suppl 2]: 789-830

28. Keen H, Jarrett RJ, Fuller J (1973) Tolbutamide and arterial disease in borderline diabetics. Excerpta Medica Int Congress Series 312: 588-602

29. Sartor G, Schersten B, Carlstrom S, Melander A, Norden A, Persson $G$ (1980) Ten-year follow-up of subjects with impaired glucose tolerance. Prevention of diabetes by tolbutamide and diet regulation. Diabetes 29: 41-49

30. The DCCT Research Group (1986) The diabetes control and complications trial (DCCT): design and methodologic considerations for the feasibility phase. Diabetes $35: 530-544$
31. Hermann LS (1979) Metformin: a review of its pharmacological properties and therapeutic use. Diab Metab Rev 5: 233-245

32. Standl E, Stiegler H, Roth R, Schulz K, Lehmacher W (1989) On the impact of hypertension on the prognosis of NIDDM. Results of the Schwabing GP-Program. Diab Metab 15:352-358

33. Medical Research Council Working Party (1985) MRC trial of treatment of mild hypertension: principal results. Br Med J 291: 97-104

34. Australian National Blood Pressure Study Management Committee (1980) The Australian Therapeutic trial in nild hypertension. Lancet I: 1261-1267

35. Collins R, Peto R, MacMahon S et al. (1990) Blood pressure, stroke, and coronary heart disease: part 2 , short-term reductions in blood pressure: overview of randomised drug trials in their epidemiological context. Lancet 335: 827-838

36. Chobanian AV (1986) Antihypertensive therapy in evolution. N Engl J Med 314: 1701-1702

37. Christensen CK, Mogensen CE (1987) Antihypertensive treatment: long-term reversal of progression of albuminuria in incipient diabetic nephropathy. A longitudinal study of renal function. J Diab Compl 1: 45-52

38. Mogensen CE (1982) Long term antihypertensive treatment inhibiting progression of diabetic nephropathy. $\mathrm{Br}$ Med J 285: 685688

39. Parving H-H, Anderson AR, Smidt UM, Hommel E, Mathiesen ER, Svendsen PA (1987) Effect of antihypertensive treatment on kidney function in diabetic nephropathy. Br J Med 294: 14431447

40. Mathiesen ER, Borch-Johnsen K, Jensen DV, Deckert T (1989) Improved survival in patients with diabetic nephropathy. Diabetologia 32: 884-886

41. Yusuf S, Peto R, Lewis J, Collins R, Sleight P (1985) Beta blockade during and after myocardial infarction: an overview of the randomised trials. Prog Cardiovasc Dis 27:335-371

42. Wilkstrand J, Warnold I, Olsson G, Tuomilehto J, Elmfeldt D, Berglund G (1988) Primary prevention with metoprolol in patients with hypertension. JAMA 259: 1976-1982

43. Hommel E, Parving HH, Mathiesen E, Edsberg B, Nielsen MD, Giese J (1986) Effect of captopril on kidney function in insulindependent diabetic patients with nephropathy. Br Med J 293: $467-470$

44. Parving HH, Hommel E, Damkjær Nielsen M, Giese J (1989) Effect of captopril on blood pressure and kidney function in normotensive insulin dependent diabetics with nephropathy. Br Med J 299: 533-536

45. Hostetter TH, Rennke HG, Brenner BM (1982) The case for intrarenal hypertension in the initiation and progression of diabetic and other glomerulopathies. Am J Med 72: 375-378

46. Zatz R, Rentz Dunn B, Meyer TW, Anderson S, Rennke HG, Brennen BM (1986) Prevention of diabetic glomerulopathy by pharmacological amelioration of glomerular capillary hypertension. J Clin Invest 77: 1925-1930

47. Dzau VJ (1988) Circulating versus local renin-angiotensin sys tem in cardiovascular homeostasis. Circulation 77 [Suppl 1]: $4-13$

48. Dzau VJ (1986) Significance of the vascular renin-angiotensin pathway. Hypertension 8: 553-559

49. Daemen MJAP, Lombardi DM, Bosman FT, Schwartz SM (1991) Angiotensin II induces smooth muscle cell proliferation in the normal and injured rat arterial wall. Circ Res 68: 450-456

50. Alderman MH, Madhavan S, Ooi WL, Cohen H, Sealey JE, Ranagh JH (1991) Association of the renin-sodium profile with the risk of myocardial infarction in patients with hypertension. $\mathrm{N}$ Engl J Med 324: 1098-1104

51. Deat VJ (1991) Renin and myocardial infarction in hypertension. N Engl J Med 324: 1128-1130

52. Abert G, Ferrer P (1990) Effects of captopil on atherosclerosis in cynomolgus monkeys. J Cardiovase Pharm 15: S65-S72

53. Powell JS, Clozel JP, Muller RKM et al. (1989) Inhibitors of angiotensin-converting enzyme prevent myointimal proliferation after vascular injury. Science 245: 186-188 
54. Sawicki PT, Mühlhauser I, Baba T, Berger M (1990) Do angiotensin converting enzyme inhibitors represent a progress in hypertension care in diabetes mellitus? Diabetologia 33: 121-124

55. United Kingdom Prospective Diabetes Study (1985) III. Prevalence of hypertension and hypotensive therapy in patients with newly diagnosed diabetes. Hypertension 7 [Suppl 2]: 8-13

56. United Kingdom Prospective Diabetes Study (1983) I. Effect of diet, sulphonylurea, insulin or biguanide therapy on fasting plasma glucose and body weight over one year. Diabetologia 24:404 411

57. Holman RR, Turner RC (1978) Basal normoglycaemia attained with chlorpropamide in mild diabetes. Metabolism 27: 539-547

58. Holman RR, Steemson J, Darling P, Reeves WG, Turner RC (1984) Human ultralente insulin. Br Med J 288: 665-668

59. Metropolitan Life Insurance Company (1959) New weight standard for men and women. Stat Bull Metropolitan Life 40:1 4

60. Holman RR, Turner RC (1985) A practical guide to basal and prandial insulin therapy. Diab Med 2:45-53

61. Phillips M, Simpson RW, Holman RR, Turner RC (1979) A simple and rational twice daily subcutaneous insulin regime. Distinction between basal and meal insulin requirement. Quart $\mathrm{J}$ Med 48: 493-506

62. Turner RC, Holman RR, Matthews DR (1988) Sulphonylurea failure and inadequacy. In: Cameron D, Colagiuri S, Heding L (eds) Excerpta Medica, Amsterdam. Novo Symposium, Hamilton Island. pp 52-56

63. United Kingdom Prospective Diabetes Study (1988) IV. Characteristics of newly-presenting type 2 diabetic patients: male preponderance and obesity at different ages. Diab Med 5: 154-159

64. United Kingdom Prospective Diabetes Study (1990) VI. Complications in newly diagnosed type 2 diabetic patients and their association with different clinical and biochemical risk factors. Diab Res 13: 1-11

65. Wright BM, Dore CF (1970) A random-zero sphygmomanometer. Lancet I: 33-35

66. Ferris FL, Kassoff A, Bresnick GH, Bailey I (1982) New visual charts for clinical research. Am J Ophthalmol 94: 91-96

67. Davis MD, Hubbard LD, Tarutmann J (1985) Studies of retinopathy; methodology assessment and classification with fundus photographs. Diabetes 35 [Suppl]: $42-49$

68. Bloom S, Till S, Sonksen P, Smith S (1984) Use of a biothesiometer to measure individual vibration thresholds and their variation in 519 non-diabetic subjects. Br J Med 288: 1793-1795

69. Ewing DJ, Borsey DQ, Bellavere F, Clarke BF (1981) Cardiac autonomic neuropathy in diabetes: comparison of measures of R-R interval variation. Diabetologia $21: 18-24$

70. Ewing DJ, Campbell IW, Murray A, Neilson JMM, Clarke BF (1978) Immediate heart-rate response to standing: simple test for autonomic neuropathy in diabetes. Br Med J 1:145-147

71. Rose GA, Blackburn H, Gillum RF, Prineas RJ (1982) Cardiovascular survey methods, 2nd edn. World Health Organisation, Geneva

72. Davis JE, McDonald JM, Jarett L (1978) A high performance liquid chromatography method for haemoglobin $\mathrm{A}_{\mathrm{lc}}$. Diabetes 27: 102-107

73. Wahlefeld AW (1974) Triglycerides. Determination after enzymatic hydrolysis. In: Bergmeyer M (ed) Methods of enzymatic analysis, 2nd edn, Vol.4. Verlag Chemie, Weinheim and Academic Press, New York London, pp 1831-1835
74. Siedel J, Schlumberger H, Klose S, Ziegenhorn J, Wahlefeld AW (1981) Improved reagent for the enzymatic determination of serum cholesterol. J Clin Chem Clin Biochem 19: 838-839

75. Burstein M, Scholnick HR, Morfin R (1970) Rapid method for the isolation of lipoproteins from human serum by precipitation with polyanions. J Lipid Res 11: 583-594

76. Moore JC, Morris JE (1982) A simple automated colorimetric method for determination of $\mathrm{N}$-acetyl-B-D-glucosaminidase. Ann Clin Biochem 19: 157-159

77. Albano JM, Ekins RP, Maritz G, Turner RC (1972) A sensitive precise radio-immunoassay of human insulin relying on charcoal separation of bound and free hormone moieties. Acta Endocrinol 70: 487-509

78. Kearney EM, Mount JN, Watts GF, Slavin BM, Kind PRN (1987) Simple immunoturbidimetric method for determining urinary albumin at low concentrations using Cobas-Bio centrifugal analyser. J Clin Path 40: 465-468

79. Henry RJ, Cannon DC, Winkelman JW (1974) Clinical chemistry; principles and technics. Harper \& Row, Hagerstown, pp 552-553

80. Ginsberg JM, Chang BS, Matarese RA, Garella S (1983) Use of single voided urine samples to estimate quantitative proteinuria. N Engl J Med 309: 1543-1546

81. Yuen CT, Kind PRN, Price RG, Praill PFG, Richardson AC (1984) Colorimetric assay for $\mathrm{N}$-acetyl-beta-D-glucosaminidase (NAG) in pathological urine using the omega W-nitrostyryl substrate: the development of a kit and the comparison of manual procedure with the automated fluorimetric method. Ann Clin Biochem 21:295-300

82. Westgard JO, Barry PL, Hunt MR (1981) A multi-rule Shewhart chart for quality control in clinical chemistry. Clin Chem 27:493 501

83. International classification of procedures in medicine (1978) World Health Organisation. Geneva

84. Jarrett RJ, Viberti GC, Argyropoulos A, Hill RD, Mahmus U, Murrells TJ (1984) Microalbuminuria predicts mortality in noninsulin-dependent diabetes. Diab Med 1:17-19

85. Mogensen CE (1986) Microalbuminuria predicts clinical proteinuria and early mortality in maturity-onset diabetes. N Engl J Med 310: 356-360

86. Schmitz A, Vaeth M (1988) Microalbuminuria: a major risk factor in non-insulin-dependent diabetes. A 10-year follow-up study of 503 patients. Diab Med 5: 126-134

87. Stratton IM, Holman RR, Oakes SM, Turner RC for UK Prospective Diabetes Study Group (1991) Randomised trial of tight blood pressure control with ACE inhibitor or B-blocker compared with less tight control in Type II diabetic patients. Diabetes 40 [Suppl 1]:369 (Abstract)

Received: 10 October 1990

and in revised form: 20 August 1991

UK Prospective Diabetes Study Group

Diabetes Research Laboratories

Radcliffe Infirmary

Woodstock Road

Oxford OX2 6HE

UK 